A COMPARATIVE STUDY OF THE DETERMINANTS OF THE RURAL WOMEN'S REPRODUCTIVE BEHAVIOR AT MINUFIYA AND ASSUIT GOVERNORATES

Hassan, Nagwa A.

Dept. of Agricultural Extension and Rural Sociology, Faculty of Agriculture, Minufiya University , Shibin El-kom, Egypt

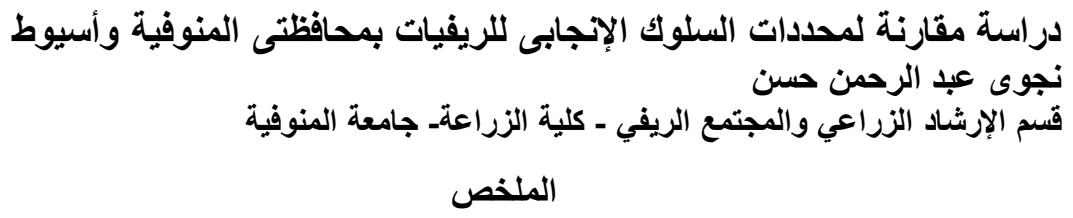

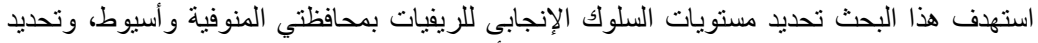

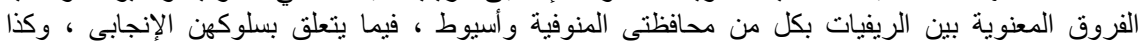

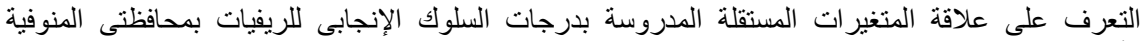

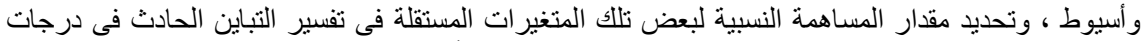

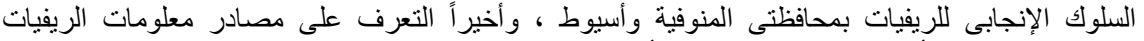

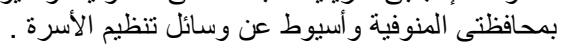

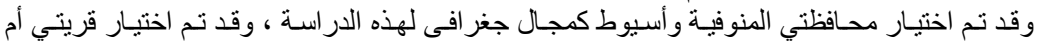

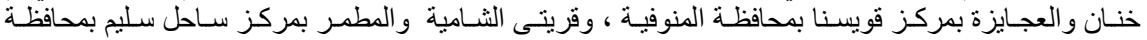

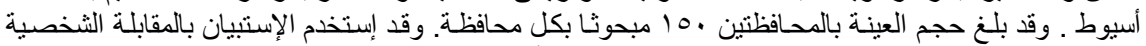

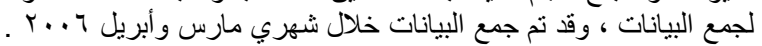

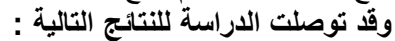

ـ ارتفاع نسبة المبحوثات الريفيات بمحافظة المنوفية في الفئة الفئة المنخفضة فى السلوك الإنجابى بنسبة 0؛

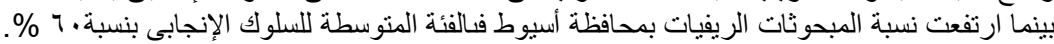

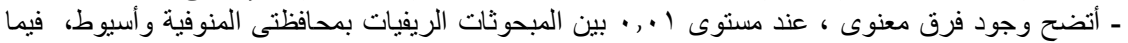

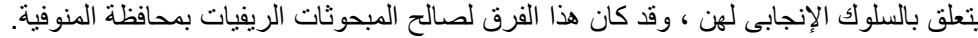

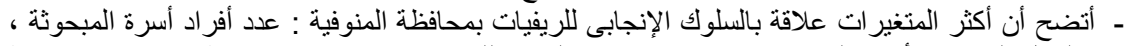

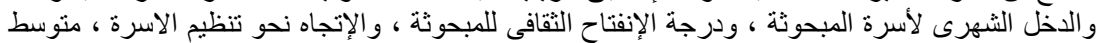

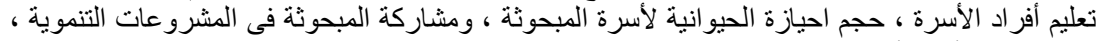

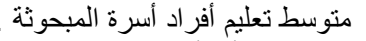

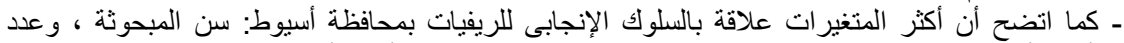

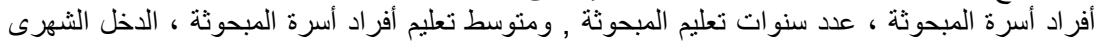

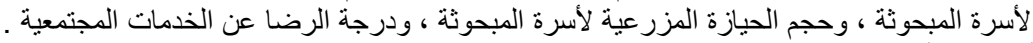

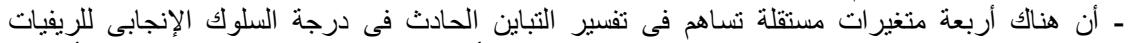

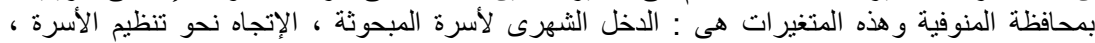

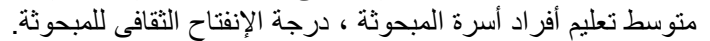

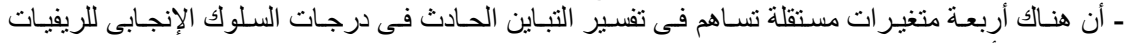

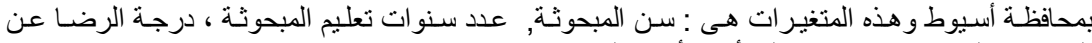
الخدمات المجتمعية ، درجة تعليم أفراد أسرة المبحوثة. لمنة.

\title{
المقدمة والمشكلة
}

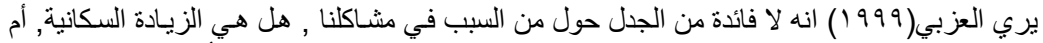

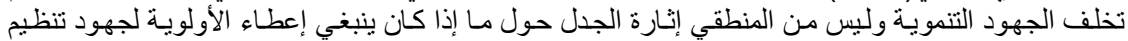

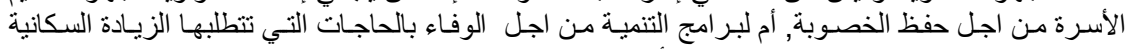

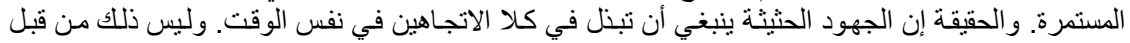


Hassan, Nagwa A.

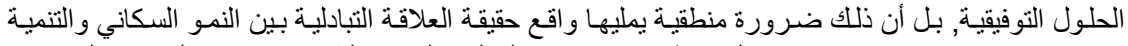

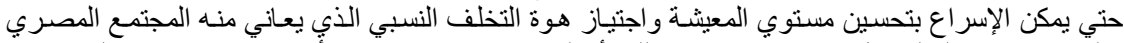

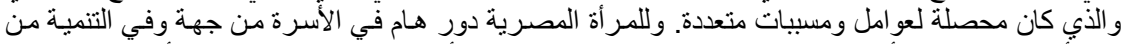

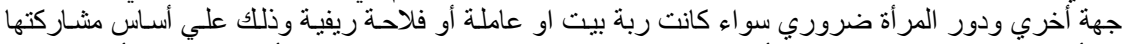

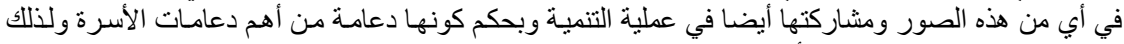

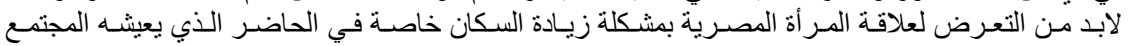

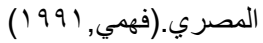

ويلعب الريفيون دورا هاما في تنمية المجتمع بصفة عامة والتنمية الريفية بصفة خاصة فهم يقومون

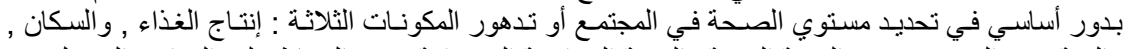

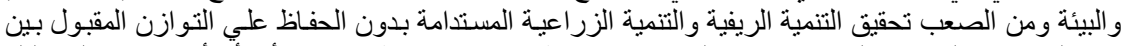

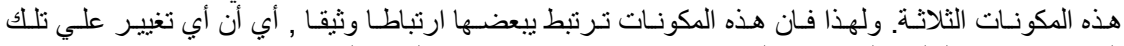

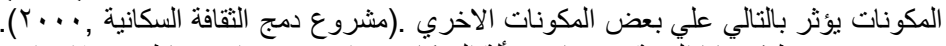

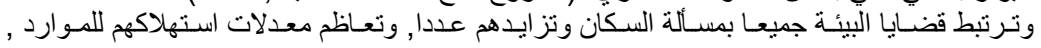

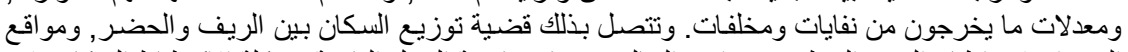

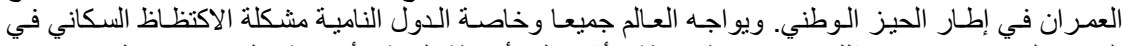

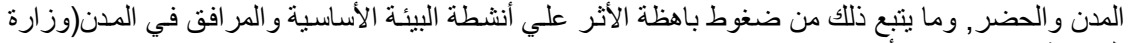

الزر اعة واستصلاح الأراضي, عـو 199).

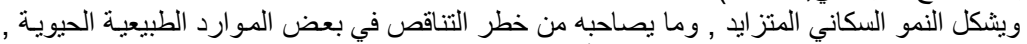

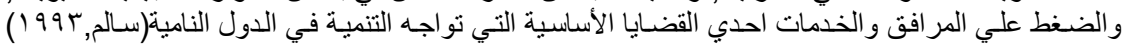

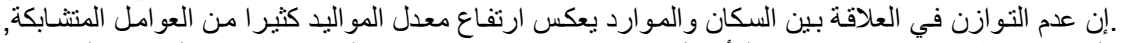

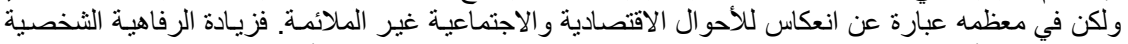

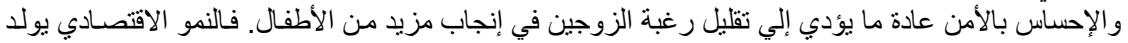

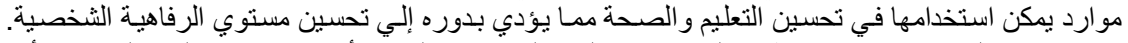

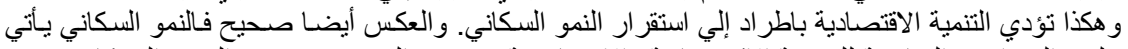

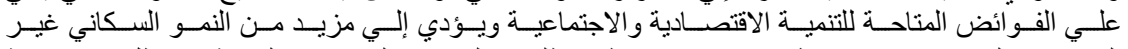

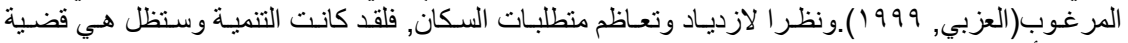

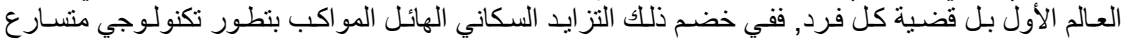

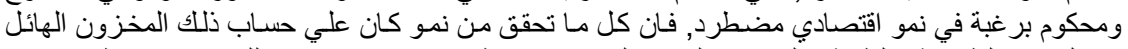

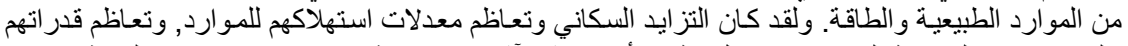

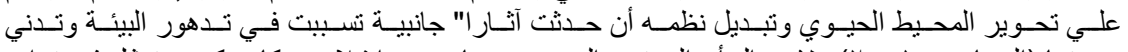

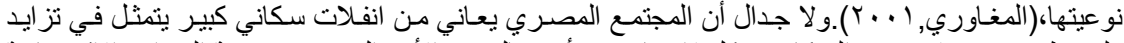

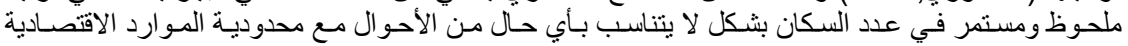

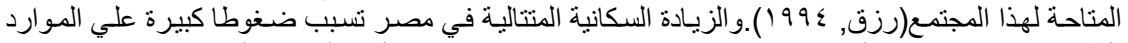

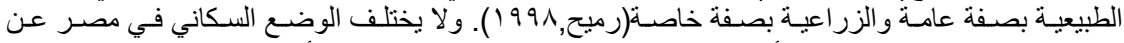

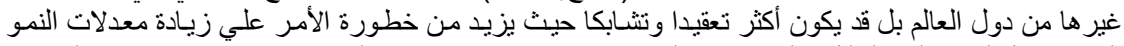

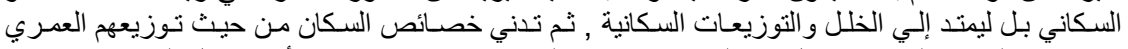

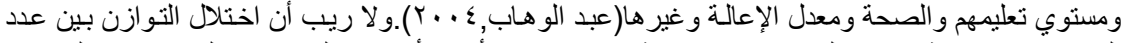

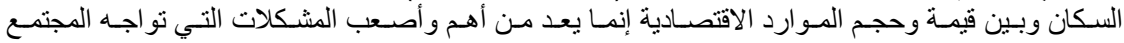

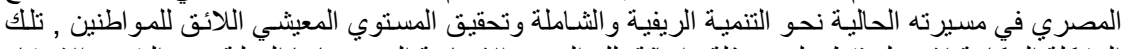

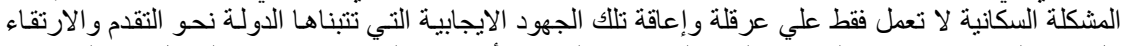

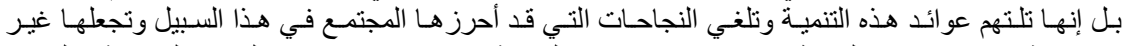

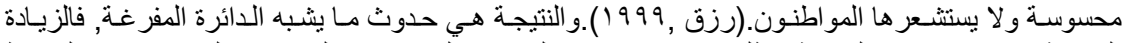

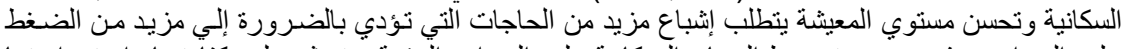

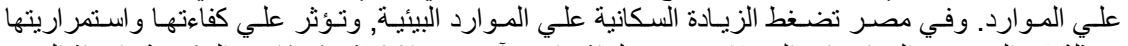

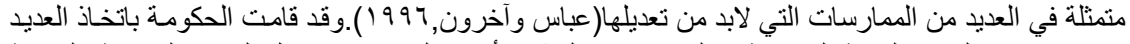

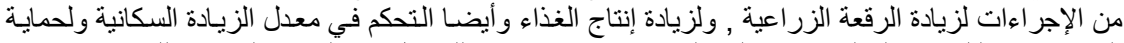

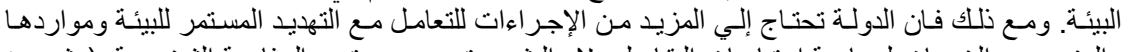

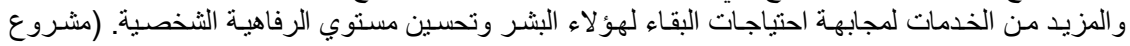




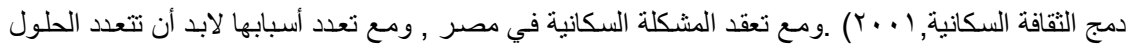

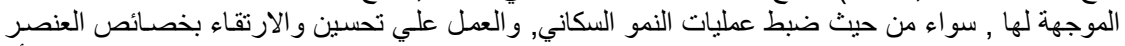

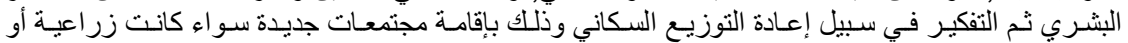

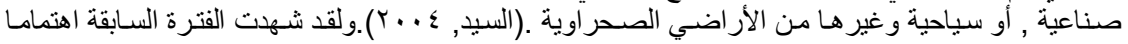

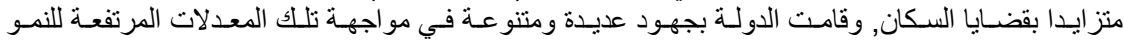

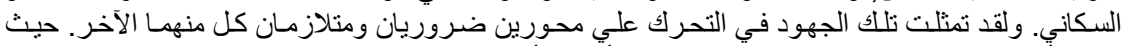

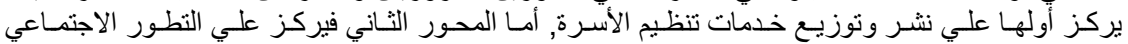

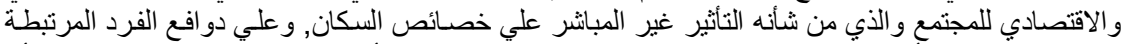

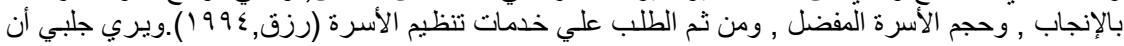

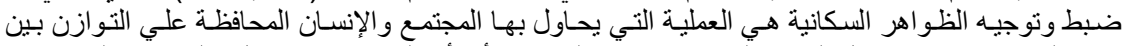

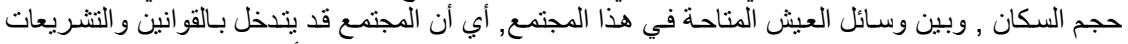

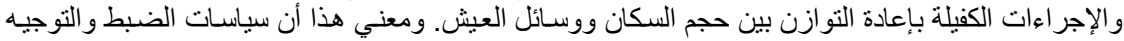

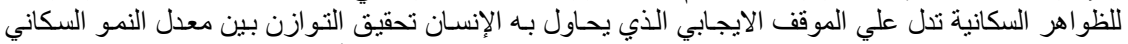

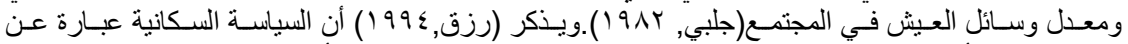

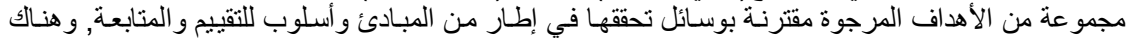

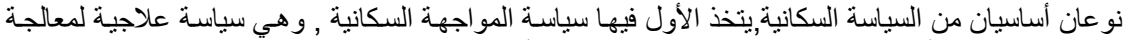

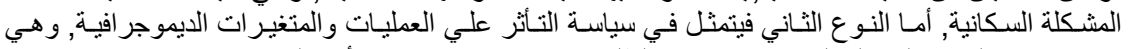

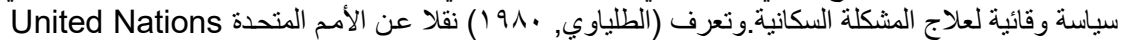

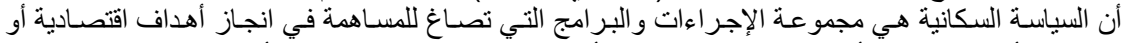

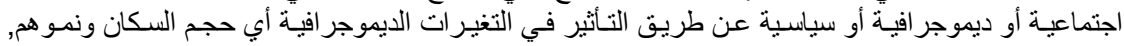

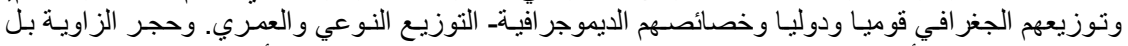

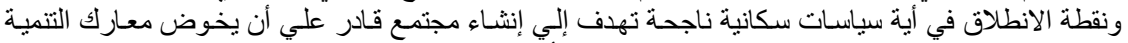

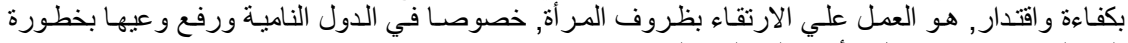

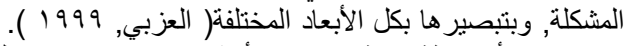

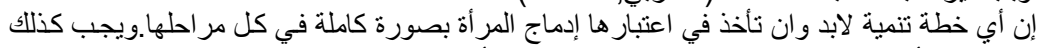

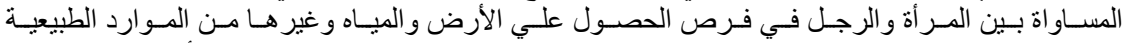

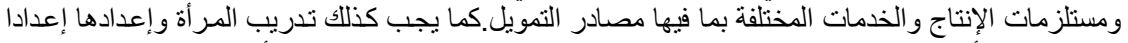

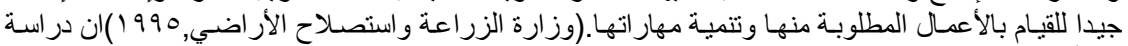

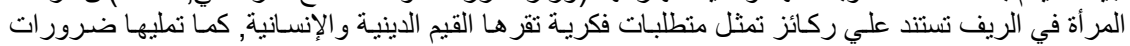

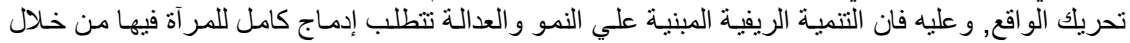

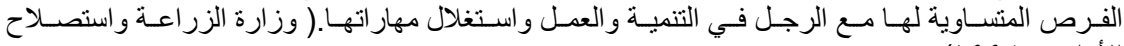

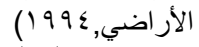

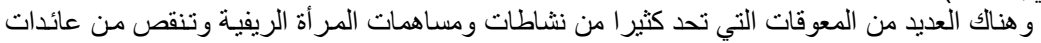

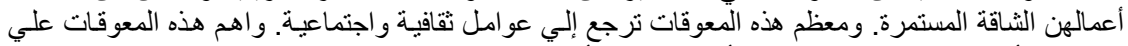

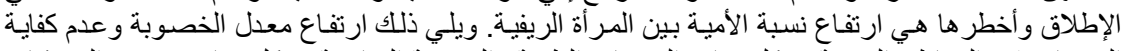

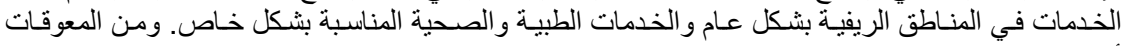

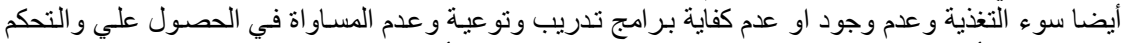

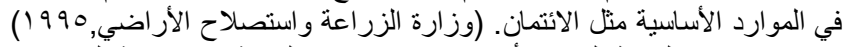

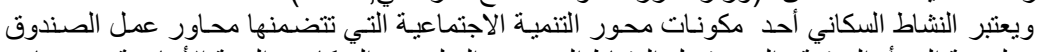

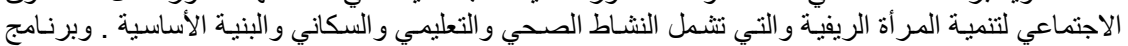

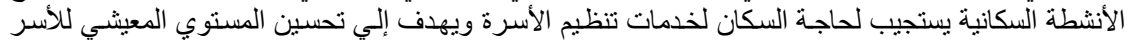

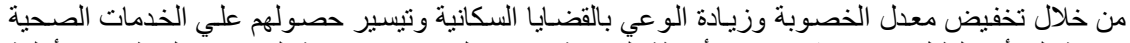

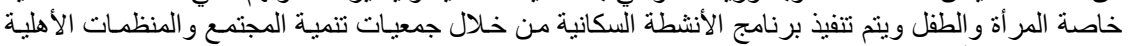

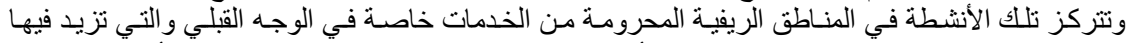

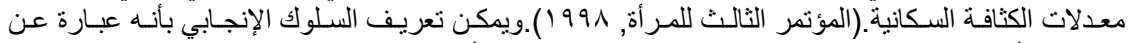

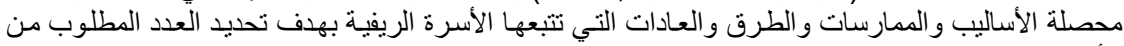

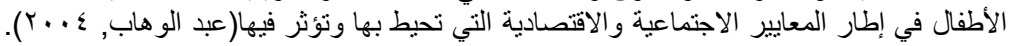


Hassan, Nagwa A.

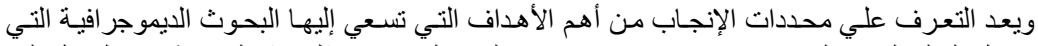

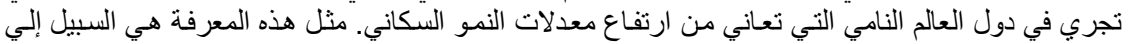

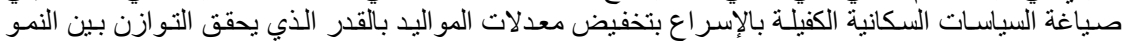

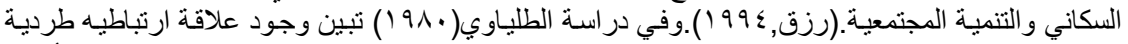

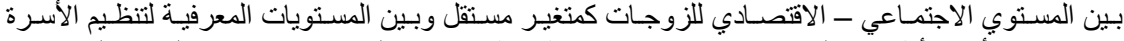

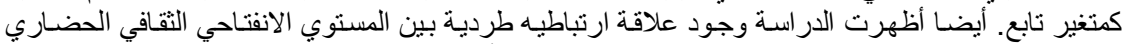

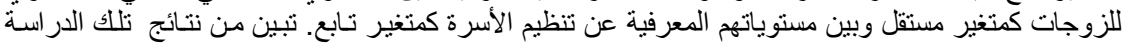

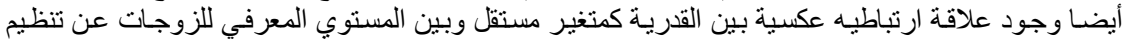

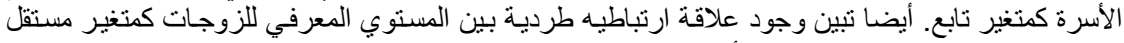

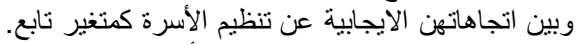

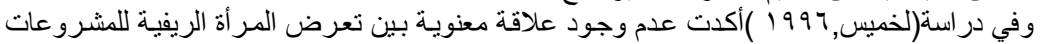

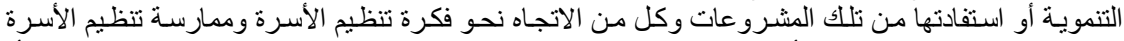

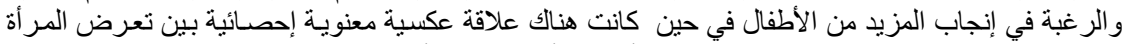

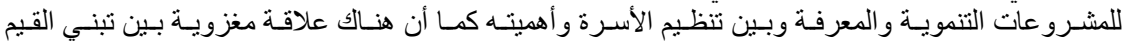

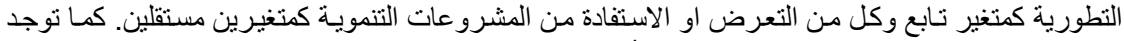

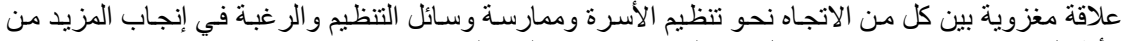

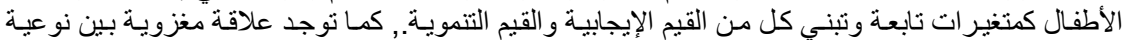

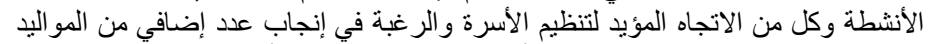

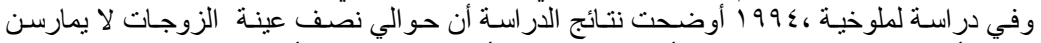

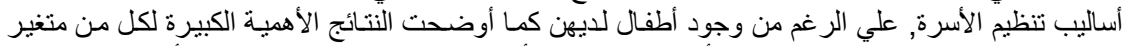

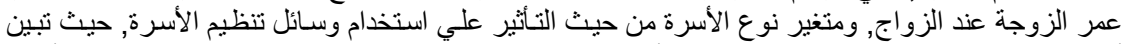

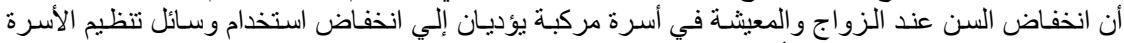

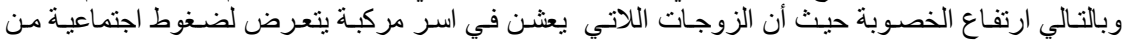

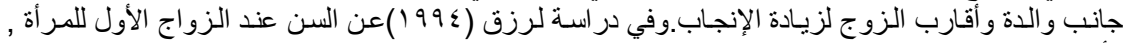

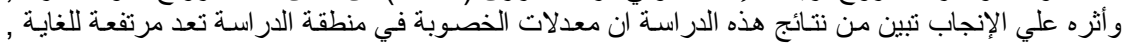

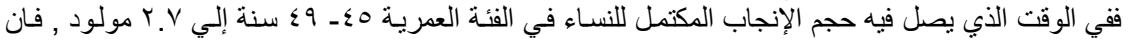

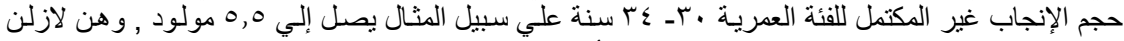

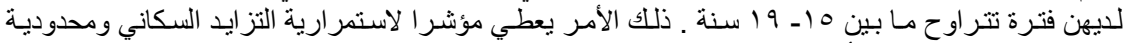

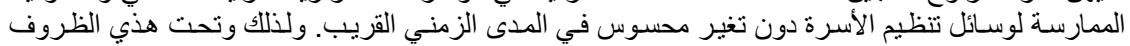

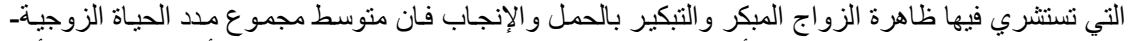

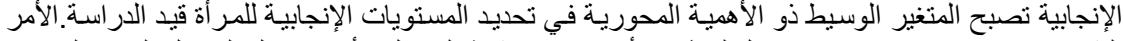

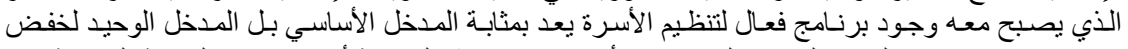

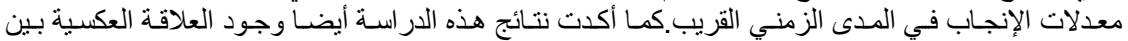

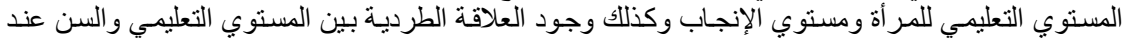

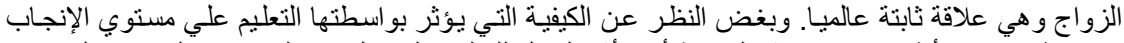

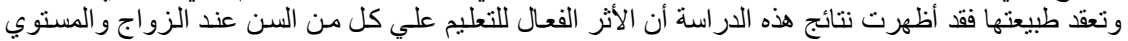

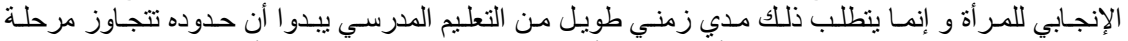

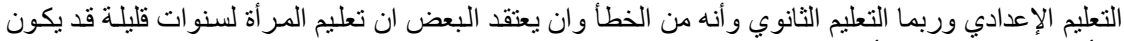

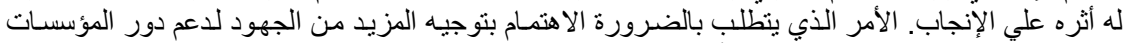

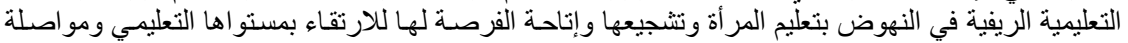

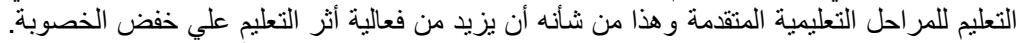

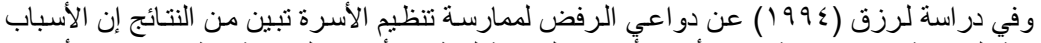

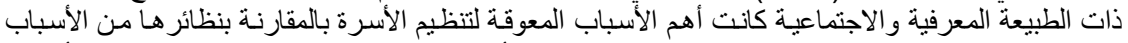

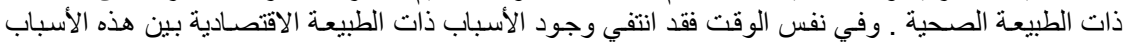

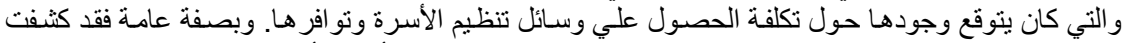

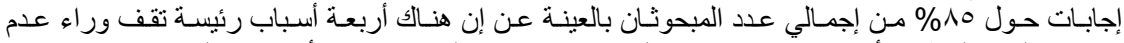

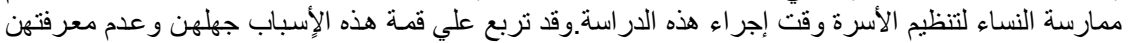

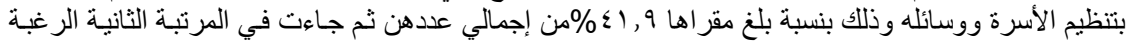




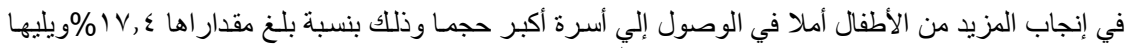

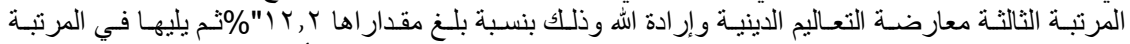

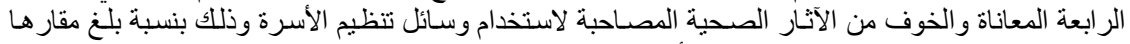

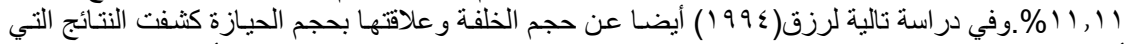

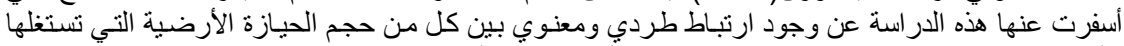

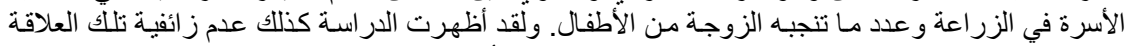

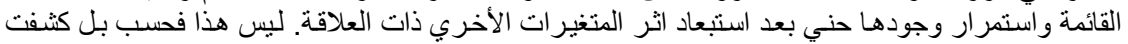

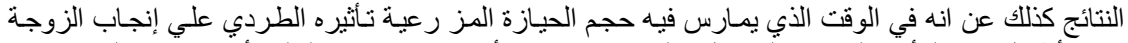

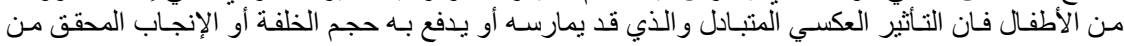

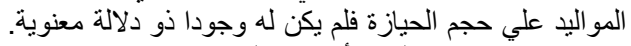

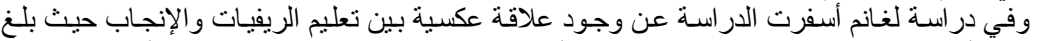

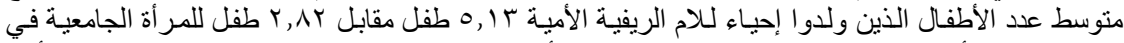

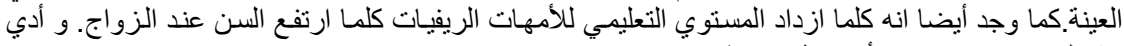

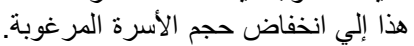

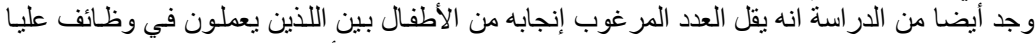

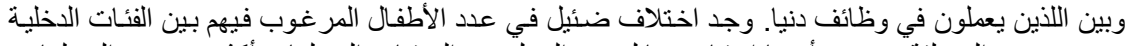

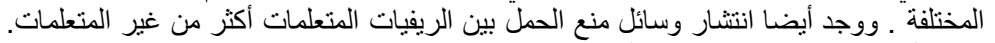
ويمكن تحديد مشكلة البحث فى التساؤلات الآتية : لإئل

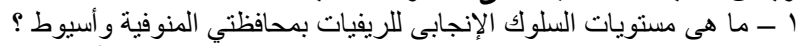

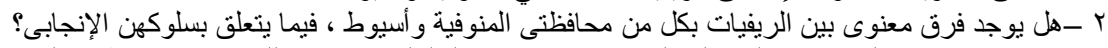

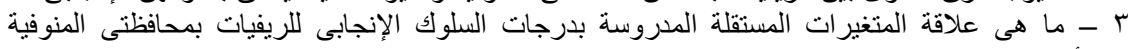
و أسيوط

ع - ما مقدار المساهمة النسبية لبعض تلك المتغير ات فى تفسير التباين الحادث فى درجات السلوك الإنجابى

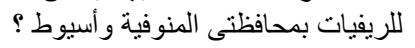

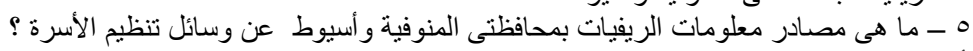

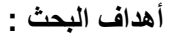

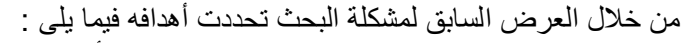

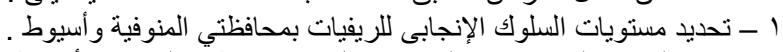

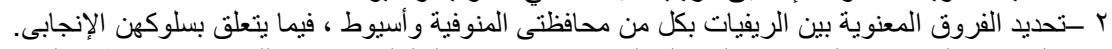
r - التعرف على علاقة المتغير ات المستقلة المدروسة بدرجات السلوك الإنجابى للريفيات بمحافظتى المنوفية لإنية و أسيوط التعرف ـ ـ تحديد مقدار المساهمة النسبية لبعض تلإلك المتغيرات المستقلة فى تفسير التباين الحادث فى درجات السلوك

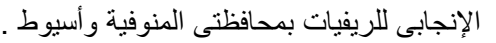

0 - التعرف على مصادر معلومات الريفيات بمحافظتى المنوفية وأسيوط عن وسائل تنظيم الأسرة .

ولتحقيق الأهداف ( الثاني و الثنالث و الرابع ) تم صياغة الفروض النئ النظرية التالية:

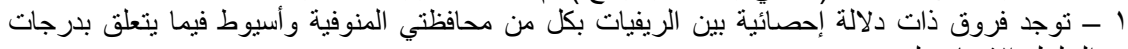

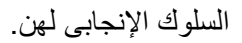
r - توجد علاقة ذات دلالة إحصائية بين المتغيرات المستقلة المدروسة ودرجات السلوك الإنجابى للريفيات بمحافظتى المنوفية وأسيوط. r - تسهم المتغيرات المستقلة المدروسة مجتمعة في تفسير التباين في درجات السلوك الإنجابى للريفيات الطريقة البحثية

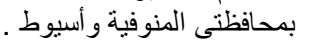
منطقة الاراسة والعينة: 
Hassan, Nagwa A.

لتحقيق أهداف هذا البحث و التى تمثلت فى التعرف على محددات السلوك الإنجابى للريفيات ، تم اختيار

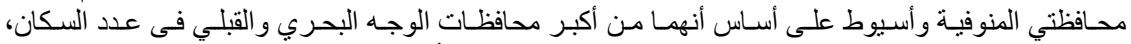

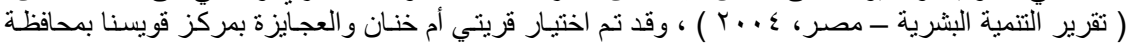

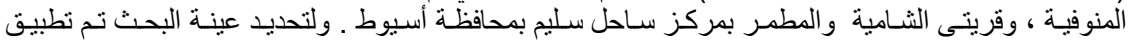

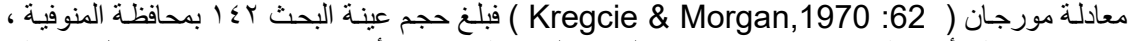

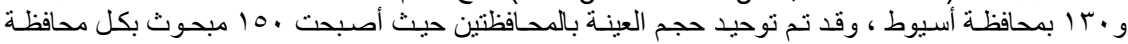
وذللك لهدف المقارنة .

طريقة جمع البيانات : مئم

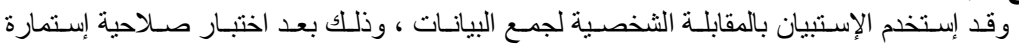

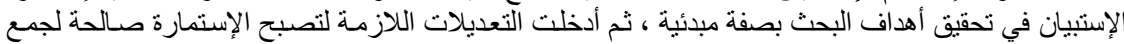

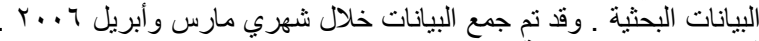

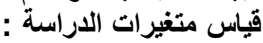

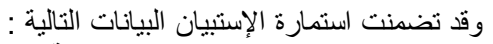

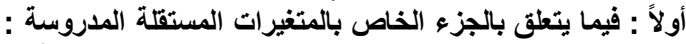

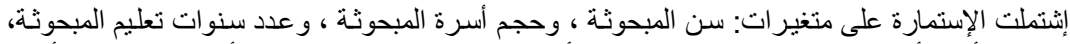

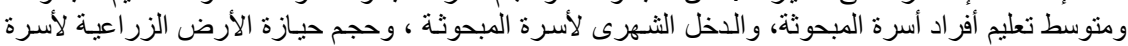

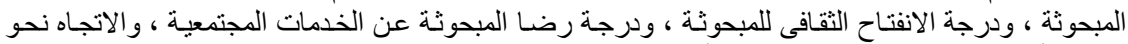

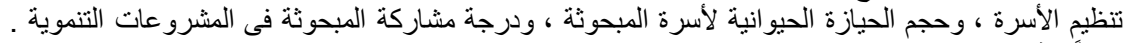

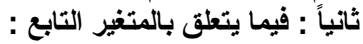

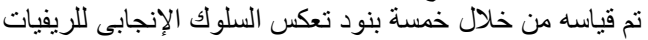

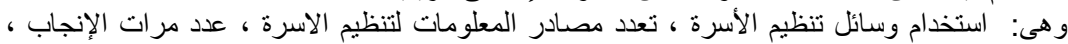

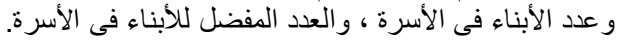
- مقاستخدام وسائل تنظيم الأسرة:

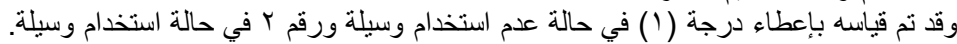

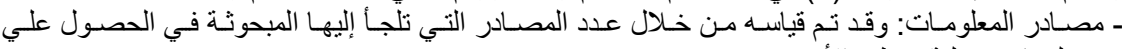

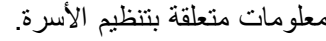

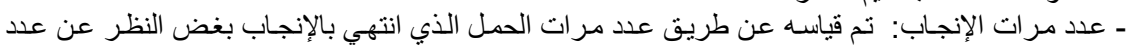

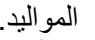

ـ ـ عدد أبناء الأسرة: وتم قياسه من خلال الرقم الخام لعدد أبناء المبحوثة سواء كانوا ذكور أو إناث.

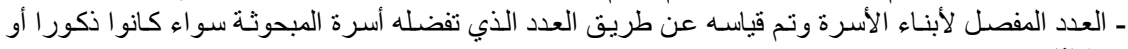
إنانا.

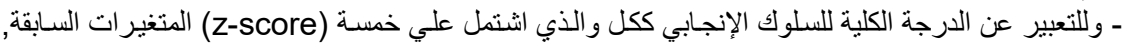

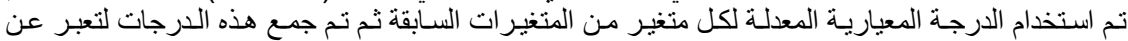
الدوجة الكلية للسلوك الإنجابي. أدوات التحليل الإحصائى : الإندي

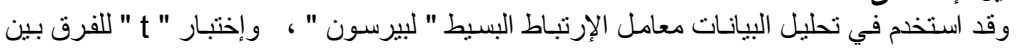

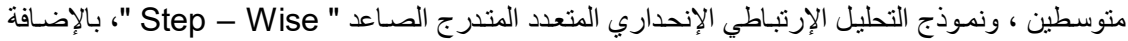

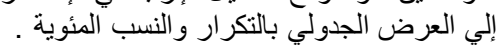

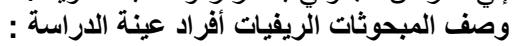

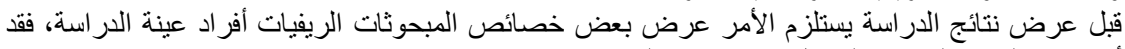

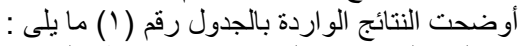

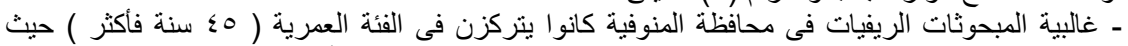

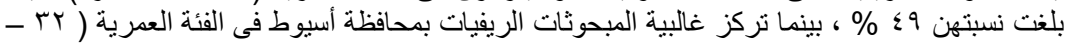

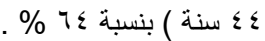

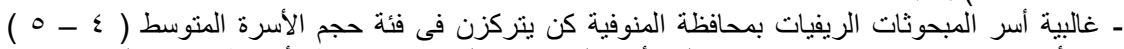

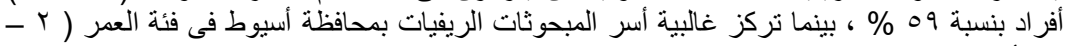

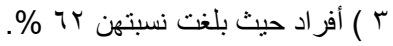


- غالبية المبحوثات الريفيات بمحافظتى الدر اسة كن يتركزن فى فئة المستوى

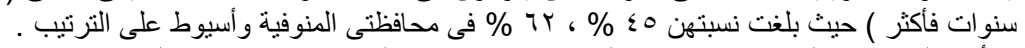

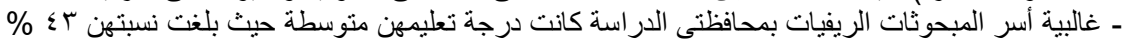

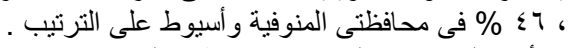

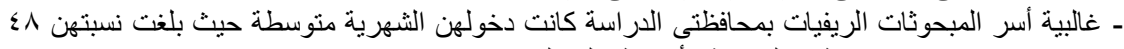

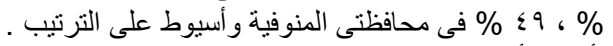

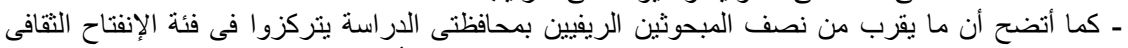

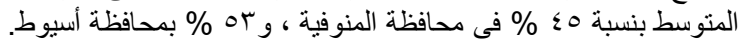

جدول رقم ( 1 ): توزيع المبحوثات الريفيات أفراد عينة البحث وفقاً لبعض خصائصهن الثخصية بمحافظتى

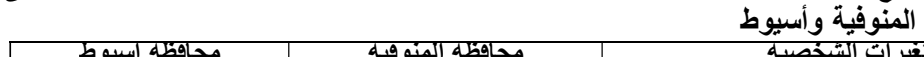

\begin{tabular}{|c|c|c|c|c|}
\hline \multicolumn{2}{|c|}{ محافظه اسيوط } & \multicolumn{2}{|c|}{ محافظه المنوفيه } & \multirow[t]{2}{*}{ المتغيرات التُخصب } \\
\hline$\%$ & عدد & $\%$ & عدد & \\
\hline & & & & 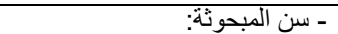 \\
\hline YT & ro & TV & 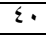 & (r) - 19) سنة \\
\hline $7 \varepsilon$ & 97 & TY & $\sum \Lambda$ & ( سنة ( $(\varepsilon \varepsilon-M)$ \\
\hline $1 \pi$ & 19 & $\leqslant 9$ & TY & (0) \\
\hline & & & & - عدد أفر اد أسرة المبحوثة \\
\hline $7 r$ & $9 \leq$ & ry & $0 \leqslant$ & صغيرة (r-r \\
\hline rY & $\leqslant V$ & 09 & $1 \Lambda$ & متوسطة ( ـ ـ 0 ) أفراد \\
\hline 7 & 9 & 0 & $\Lambda$ & كبيرة ( 7 أفراد فاكثُر ) \\
\hline & & & & ـ عدد سنو ات تعليم المبحوثة \\
\hline IT & 11 & $T \varepsilon$ & r4 & (صفر - ₹ ) سنوات \\
\hline YY & r9 & rI & $\leqslant 7$ & ) (9-0) سنوات \\
\hline $7 \pi$ & 95 & $\leqslant 0$ & 71 & ( · ( سنوات فاكثر ) \\
\hline & & & & - منوسط تعليم أسرة المبحوثة \\
\hline YV & $\varepsilon \cdot$ & \&1 & $\pi$ & ( صفر - Y) درجة \\
\hline$\leqslant 7$ & 79 & $\leqslant r$ & $7 \varepsilon$ & ) \\
\hline TV & \$1 & 17 & TE & ( ( درجات فاكثر ) \\
\hline & & & & ــ الدخل الثهرى لاسرة المبحوثة \\
\hline TO & TN & Tा & $\leqslant 7$ & 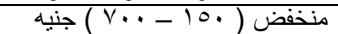 \\
\hline$\leqslant 9$ & $V T$ & $\leqslant \Lambda$ & VY & 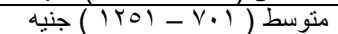 \\
\hline YT & r9 & TI & TY & عالى ( ror ( جنيه فاكثر ) \\
\hline & & & & ــ الإنفتاح الثُقافى للمبحوثة : \\
\hline 11 & 17 & TY & ro & منخفضض ( صفر - ז) درجات \\
\hline or & 19 & $\leqslant 0$ & 71 & متوسط ( ؟ - V ) درجات \\
\hline ri & 00 & Tr & $\leqslant V$ & عالى ( ^ درجات فأكثر ) \\
\hline
\end{tabular}

أولاً: مستوى السلوك الإنجابى للريفيات بمحافظتى الدراسة:

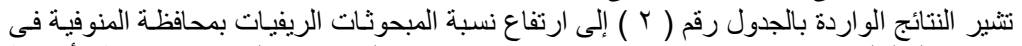

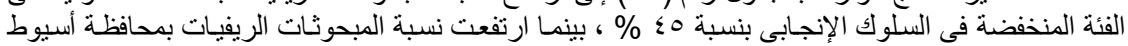

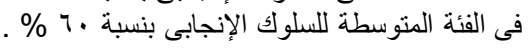

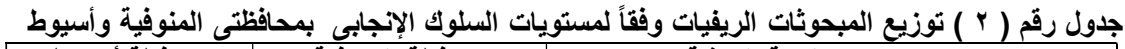

\begin{tabular}{|c|c|c|c|c|}
\hline \multicolumn{2}{|c|}{ محافظة أسيوط } & \multicolumn{2}{|c|}{ محافظة المنوفية } & \multirow[t]{2}{*}{ العينة البحثية } \\
\hline $10 .=\dot{0} \%$ & عدد & $10 \cdot=\dot{0} \%$ & عدد & \\
\hline ro & TV & $\leqslant 0$ & $V$. & 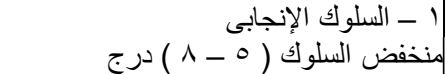 \\
\hline 7. & 9. & $\varepsilon \varepsilon$ & $7 \leq$ & متوسط السلوك (' 9 - rا' ) درجة \\
\hline
\end{tabular}


Hassan, Nagwa A.

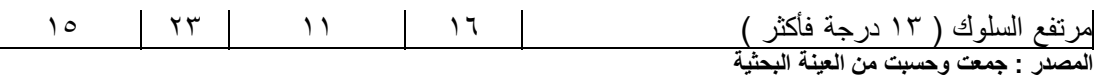

ثثانياً : تحديد معنوية الفروق بين المبحوثات الريفيات ـ أفراد عينة الاراسة ـ بمحافظتى المنوفية وأسيوط

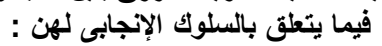

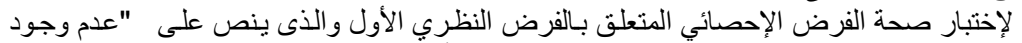

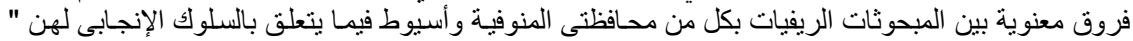

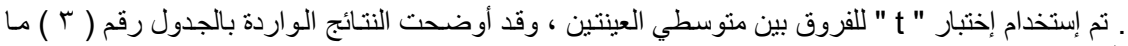

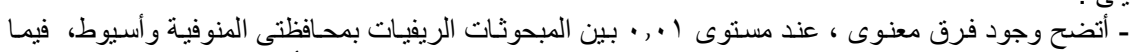

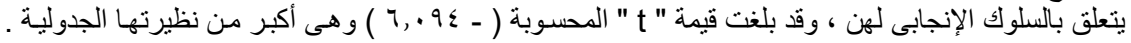
وقد كان هذا الفرق لصالح المبحوثات الريفات ليفيات بمحافظة المنوفية.

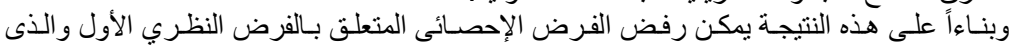

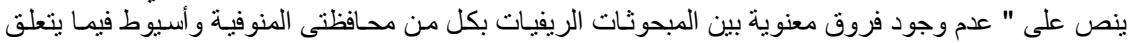

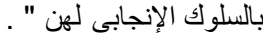

جدول رقم (َّ) : الفروق بين المبحوثات الريفيات فيما يتعلق بدرجة سلوكهن الإنجابى بمحافظتى المنوفية

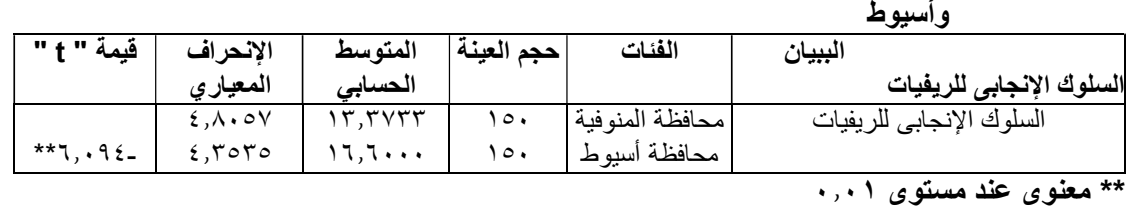

ثالثاً : علاقة المتفيرات المستقلة المدروسة بدرجات السلوك الإنجابى للريفيات بمحافظتي المنوفية وأسيوط:

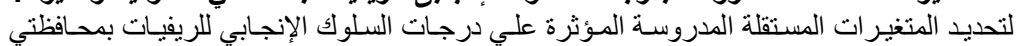

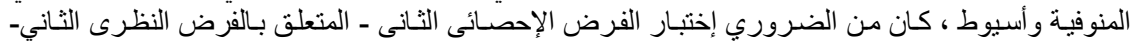

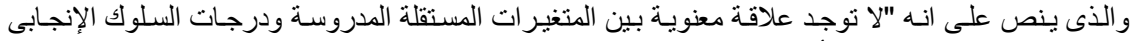

للاريفيات بمحافظني المنوفية وأسيوط ".

ولاختبار معنوية هذه العلاقة، تم إستخدام معامل الإرتباط البسيط " لبيرسون " ، وقد توصلت النتائج إلى مـا إلي : بالنسبة لمحافظة المنوفية: أثنارت البيانات الواردة بالجدول رقم ( ع ) ) إلى ما يلى:

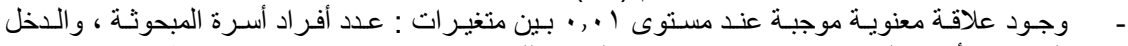

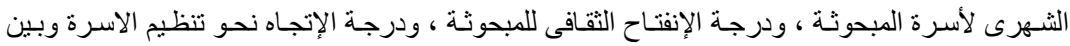

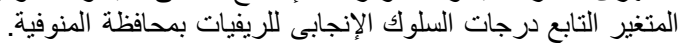

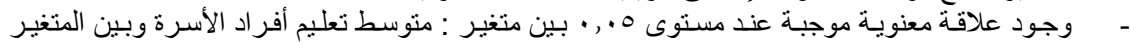
التابع درجات السلوك الإنجابى للريفيات بمحافظة المنوفية.

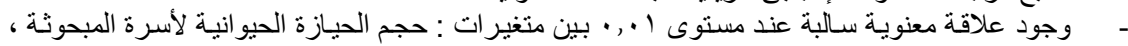

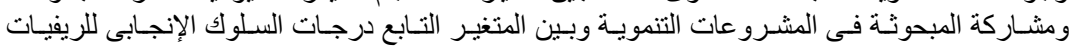
بمحافظة المنوفية.

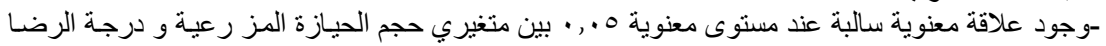
عن الخدمات المجتمعية وبين المتغير التابع: درجات السلوكية البون الإنجابي للريفيات بمحافظة المنوفية.

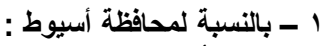

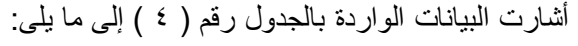


ـ وجود علاقة معنوية موجبة عند مستوى ا . , • بين متغيرات : سن المبحوثة ، و وعدد أفراد أسرة المبحوثة

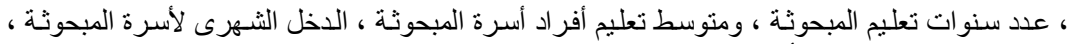

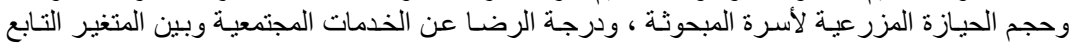

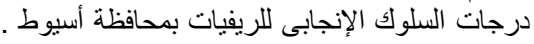

جدول رقم (؛): قيم معاملات الارتباط البسيط للعلاقة بين المتغيرات المستقلة المدروسـة ودرجات السلوك

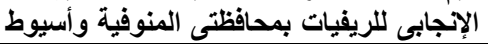

\begin{tabular}{|c|c|c|}
\hline \multicolumn{2}{|c|}{ قيم معاملات الإرتباط البسيط } & \multirow[t]{2}{*}{ المتغيرات المستقلة } \\
\hline محافظة أسيوط & محافظة المنوفية & \\
\hline$* * ., 719$ & $\cdot, \cdot \wedge \wedge$ & 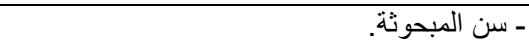 \\
\hline **., TVT & **,, ४०9 & ـ عدد أفر اد أسرة المبحوثة. \\
\hline$* *$, *^フ &., $.0 \mathrm{~V}$ & ـ عدد سنوات تعليم المبحوثة. \\
\hline **., $\leqslant 0$. & $*_{\cdot}^{*}, 1 \wedge \varepsilon$ & -متوسط تعليم أفر اد أسرة المبحوثة. \\
\hline **, 190 & $* *,, \leqslant 9 \wedge$ & ـ ـ الدخل الثهري لأسرة المبحوثة. \\
\hline **,,$\varepsilon \cdot Y$ & $*_{\cdot}^{*}, 1 \vee 9$ & - حجم الحيازة المز رعبة لأسرة المبحوثة. \\
\hline$\cdot, \ldots 9$ & **, YY. & - درجة الانفتاح الثقافي للمبحوثة \\
\hline **., YV & $*, 170_{-}$ & ـ درجة الرضا عن الخدمات المجتمعية \\
\hline., .70 & $* *,, \leq \wedge 9$ & - درجة الإتجاه نحو تنظيم الاسرة. \\
\hline$\cdot, 1 Y V_{-}$ & **, rV.- & - حجم الحيازة الحيو انية لأسرة المبحوثة. \\
\hline$\cdot, 179$ & $* *, \quad Y \leq Z_{-}$ & ـ درجة مشاركة المبحوثة فى المشروعات التنموية. \\
\hline
\end{tabular}

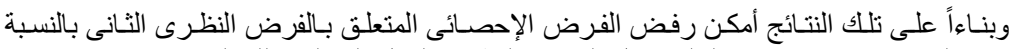

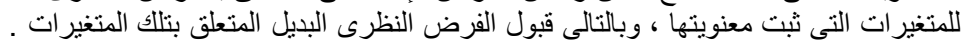

رابعاً : الإسهام النسبى للمتغيرات المستقلة المدروسة مجتمعة فى تفسير التباين الحادث فى درجات السيلوك

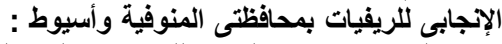

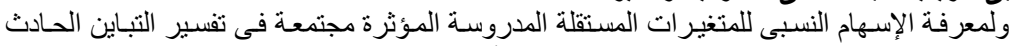

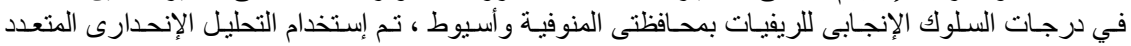

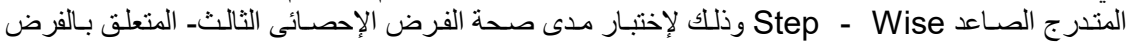

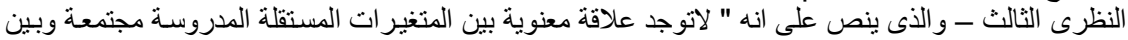

درجات السلوك الإنجابى للريفيات بمحافظتى المنوفية وأسبوط ( كمتغير تابع ) " . ل

$$
\text { وفيما يلي النتائج التي توصلت إليها الدراسة فى هذا الصدد : }
$$

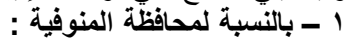

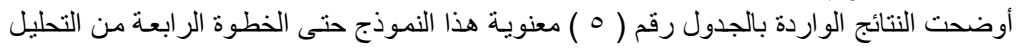

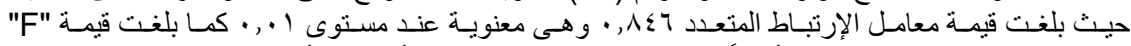

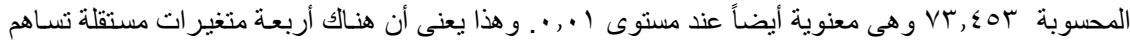

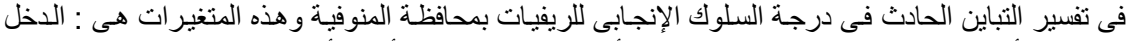

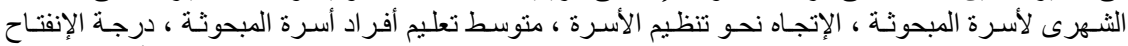

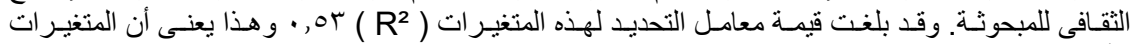

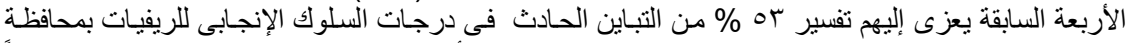

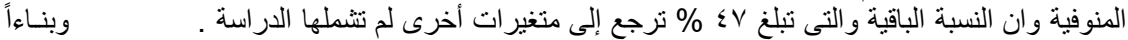

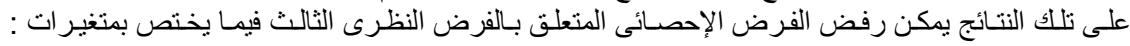


Hassan, Nagwa A.

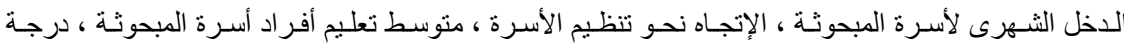

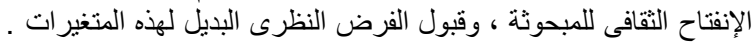

جدول رقم (0): نتائج التحليل الإحدارى المتعدد المتدرج الصـاعد للمتفيرات المستقلة المدروسـة المؤثرة

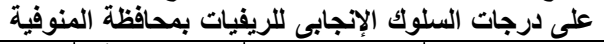

\begin{tabular}{|c|c|c|c|c|}
\hline "الاخبتار معنوية " F " الانحدار & المفسرة للتباين الحادث & 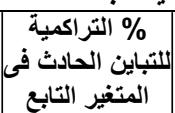 & معامل الإرتباط & |لفي التحليل المستقلة الداخلة التحليل \\
\hline$* * 11,, 107$ & $\cdot, r$. & $\cdot, \Gamma$. & $\cdot, \uparrow \cdot \varepsilon$ & |الدخل الثهري لأسرة المبحوثة \\
\hline$* * 1 \cdot r, 004$ & $\cdot, 11$ & $\cdot, \leqslant 1$ & $\cdot$, TV & |لالتجاه نحو تتظيم الأسرة \\
\hline${ }^{* *} \wedge 9, Y Y Y$ & $\cdot, \cdot \mathrm{V}$ & $\cdot, \sum \wedge$ & $\cdot, \lambda \cdot Y$ & متوسط تعليم أفراد أسرة المبحوثة \\
\hline$* * V \Gamma, \varepsilon O \Gamma$ &., .0 & $\cdot$, Or & $\cdot, \wedge \leqslant 7$ & |ردجة الانفتاح الثقافي للمبحوثة \\
\hline
\end{tabular}

ويمكن تفسير ذلك في ضوء أن التعليم يساعد علي تغيير النظرة التقليدية للمر أة الريفية كما بنمي لديها

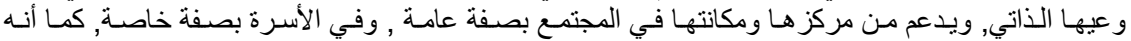

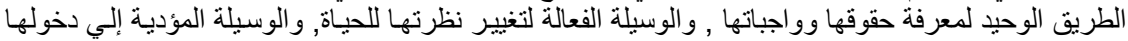

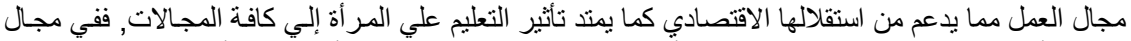

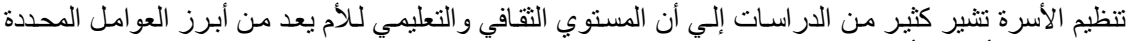

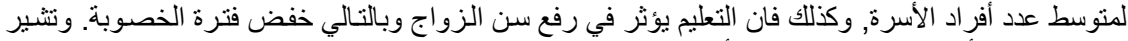

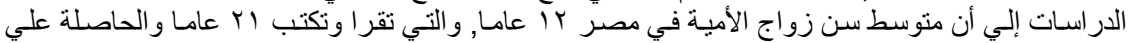

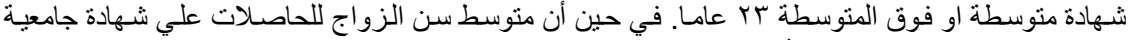

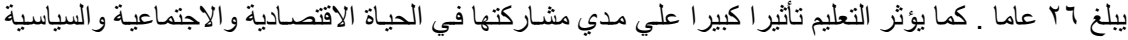

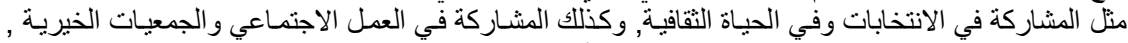

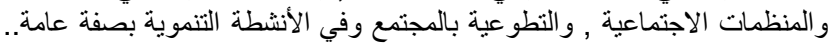

أوضحت النتائج الواردة بالجدول رقم ( 7 ) معنويـة هذا النموذج حتى الخطوة الر ابعة من التحليل

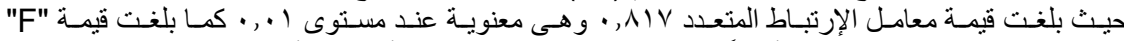

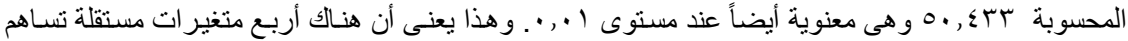

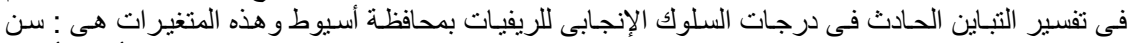

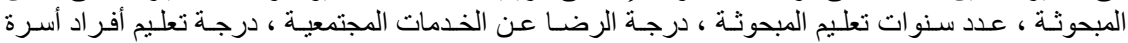

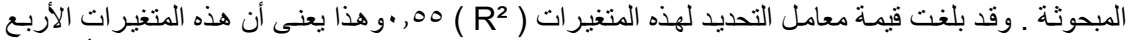

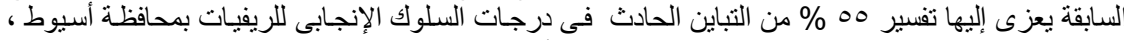

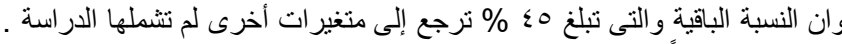

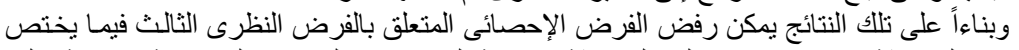

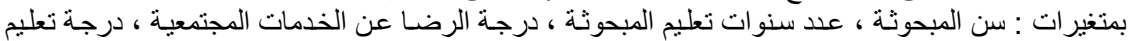
أفراد أسرة المبحوثة ، وقبول الفرض النظرى البديل لهذه المتغيرات .

جدول رقم (؟): :تتائج التحليل الإحدارى المتعدد المتدرج الصـاعد للمتغيرات المستقلة المدروسـة المؤثرة

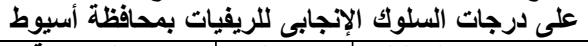

\begin{tabular}{|c|c|c|c|c|}
\hline 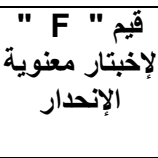 & 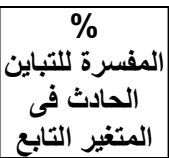 & 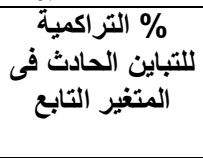 & المتارتباط & المتى التحليل المستقلة الاخلة \\
\hline$* * q 1, \wedge r q$ & $\cdot, Y \wedge$ & $\cdot, \mathrm{r} \wedge$ & $\cdot, 719$ & سن المبحوثة \\
\hline$* * \vee 0,7 r q$ & $\cdot, 1 Y$ & •, ६. & $\cdot, V \backslash r$ & عدد سنوات تعليم المبحوثة \\
\hline$* *\rceil \Lambda, 1\rceil$, & $\cdot, \cdot \wedge$ & $\cdot, \sum \Lambda$ & $\cdot, V \backslash \varepsilon$ & درجة الرضا عن الخدمات المجتمعية \\
\hline
\end{tabular}




\begin{tabular}{|c|c|c|c|c|}
\hline **0., $\leqslant \mu r$ & $\cdot, \cdot V$ & $\cdot, 00$ & $\cdot, \wedge) \mathrm{V}$ & لدرجة تعليم أفر اد أسرة المبحوثة \\
\hline
\end{tabular}

خامساً : مصادر سماع الريفيات عن وسائل تنظيم الاسرة بمحافظتى المنوفية وأسيوط:

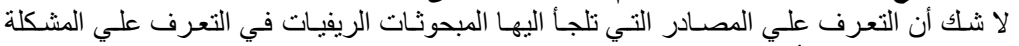

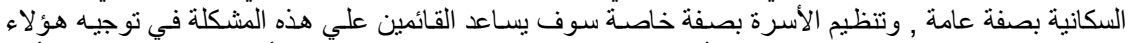

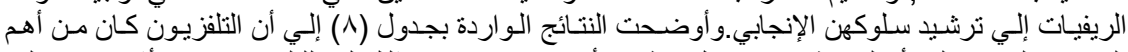

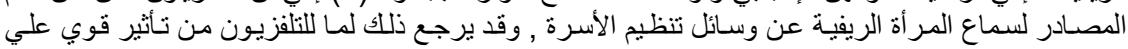

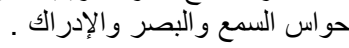

جدول رقم (^) : توزيع المبحوثات الريفيات بمحافظتى المنوفية وأسيوط وفقاً لمصسادر سماعهن عن وسـائل

\begin{tabular}{|c|c|c|c|c|}
\hline \multirow{2}{*}{\multicolumn{2}{|c|}{ محافظة أسيوط }} & \multirow{2}{*}{\multicolumn{2}{|c|}{ محافظة المنوفية }} & \multirow{2}{*}{ تلظيم الأسرة } \\
\hline & & & & \\
\hline $10 .=\dot{0} \%$ & التكرار & $10 .=\dot{0} \%$ & التكرار & \\
\hline$\leqslant 9$ & $V T$ & « & 74 & ـ التليفزيون \\
\hline ro & TV & $r q$ & 01 & ــ الر اديو \\
\hline$r$. & $r$. & Tr & $r \varepsilon$ & ـ - الأقارب \\
\hline 10 & YY & T. & $r$ r. & 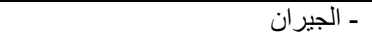 \\
\hline$\Lambda$ & IT & 1. & 10 & ـ المرشد الزراعى /المرشدة الزراعية \\
\hline 7 & 9 & 9 & $1 \pi$ & ـ ـ الر ائدة الصحية \\
\hline
\end{tabular}

المصدر : جمعت وحسبت من العينة البحثية

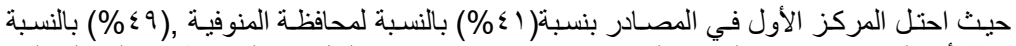

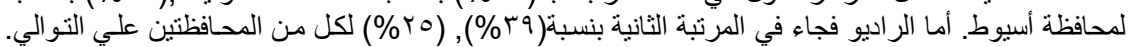

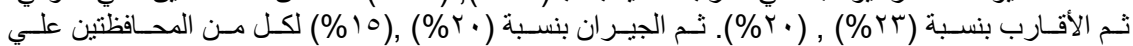

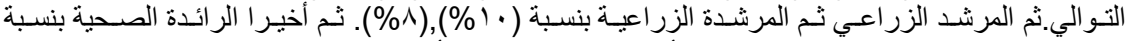

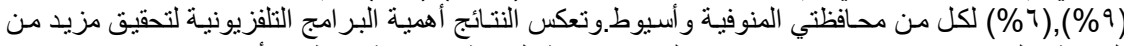
التوعية والتوجيه و الإرشاد في جميع مجالا الحياة وخاصة الصحة الإنجابية وتنظيم الأسرة.

وبناءاً على ما سبق من نتائج ، فقط توصلت الدراسة إلي مجموعة من ونئ التوصيات الهامة:

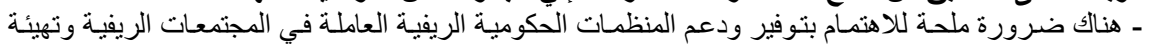

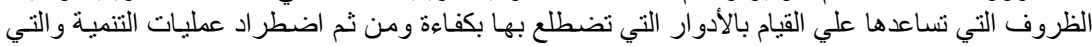

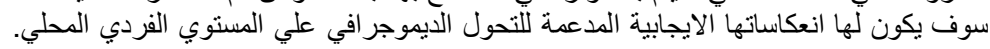

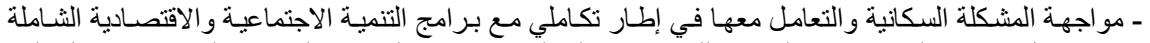

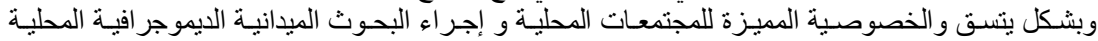

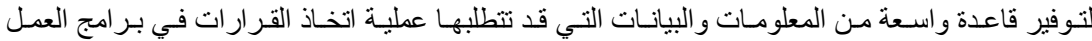

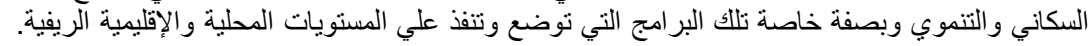

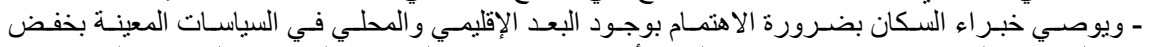

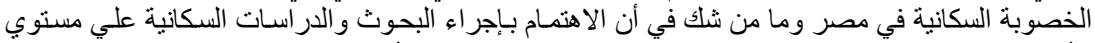

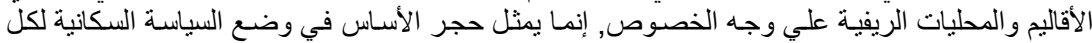

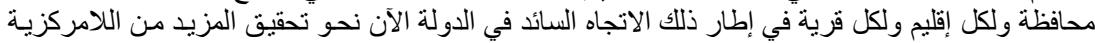

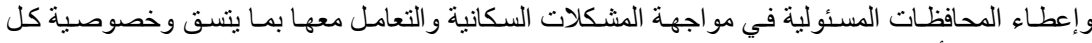

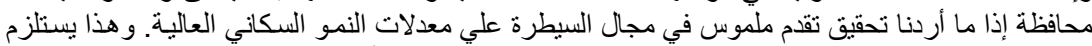

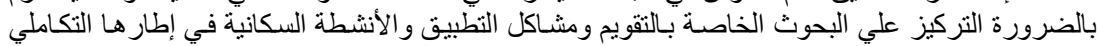

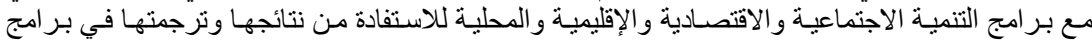
العمل السكاني الذي يتم تنفيذها إقليميا ومحليا.

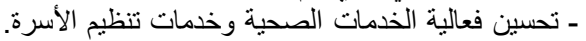

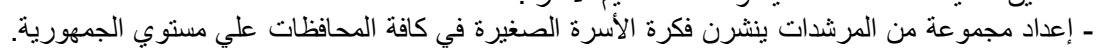
- توفير فرص عمل عن طريق المشروعات الصغيرة الصنرة 
Hassan, Nagwa A.

ـ نشـر المفهوم الثنـامل لقضية السكان وربطهـا بالعمليـة التنمويـة وزيسادة وعي السيدات لاستخدام وسـائل منع

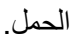

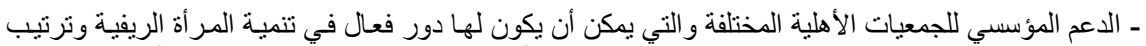

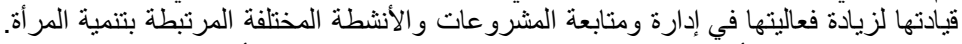

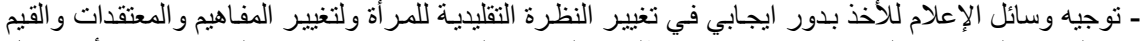

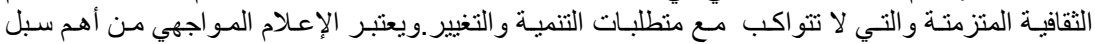

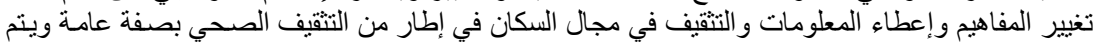

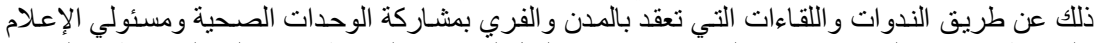

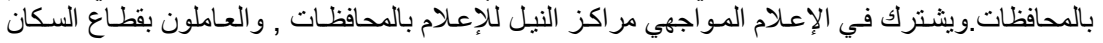

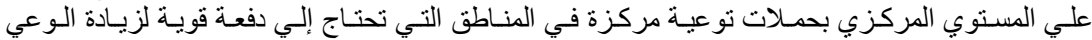

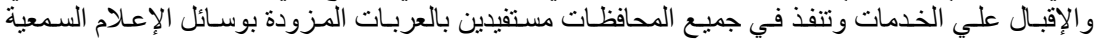

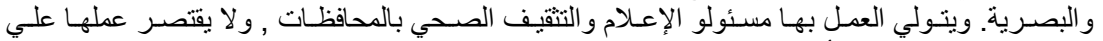

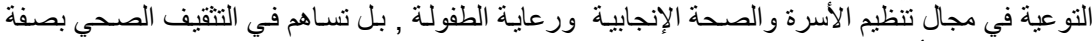

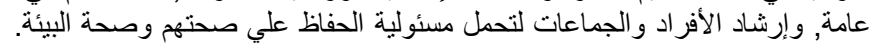

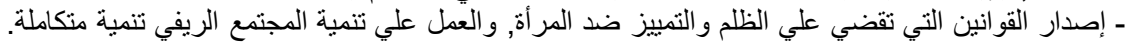

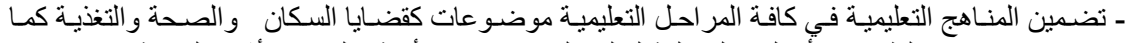

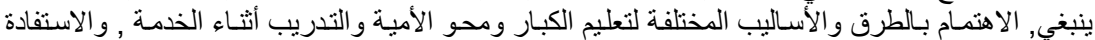

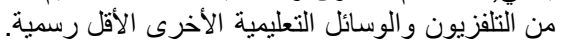

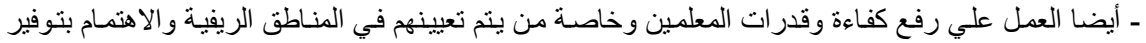

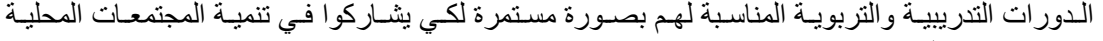
بصورة غير مبانشرة.

- حتمية إخخال قضايا المر أة الريفية في إطار ات التنمية الريفية في إطار الخطط الوطنية باعتبار ها وسيلة وهدفا,

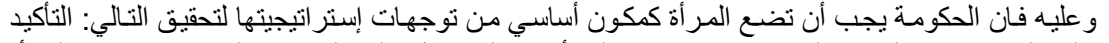

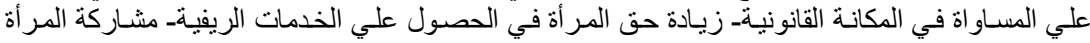

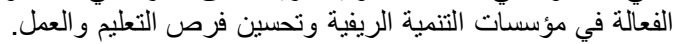

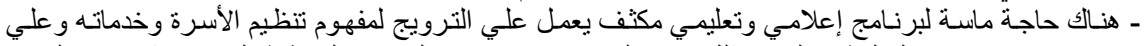

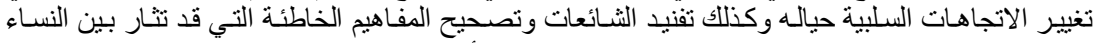

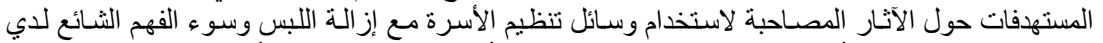

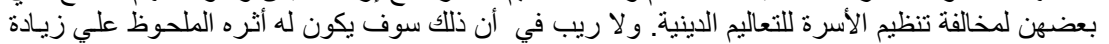

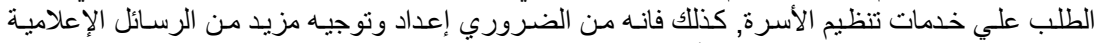

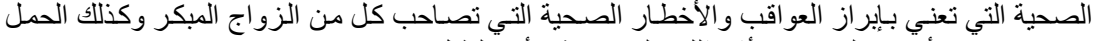
و الإنجاب في الأعمار الصغيرة وأثر ذلك علي صحة الألك الأم والطفل.

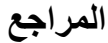

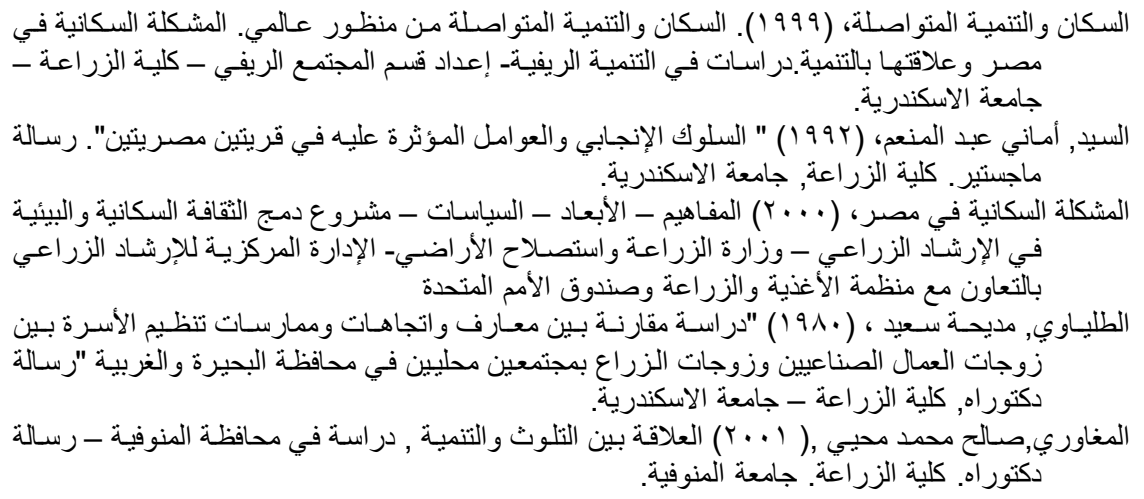


برنامج الأمم المتحدة الإنمائي, (ع . . ب) تقرير التنمية البشرية رعهد التخطيط القومي بمصر.

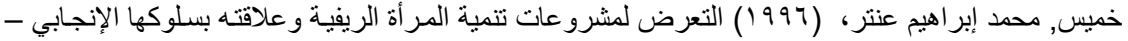

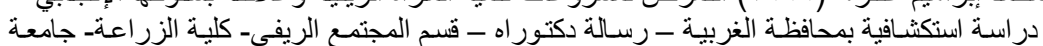
الاسكندرية.

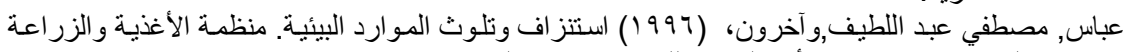

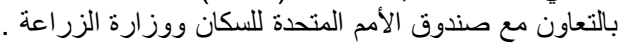

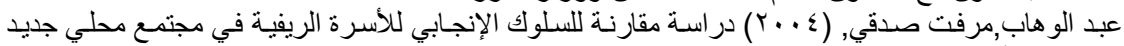

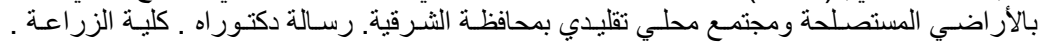
جامعة القاهرة.

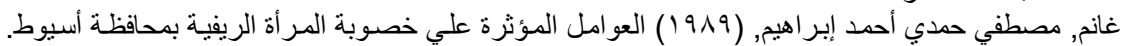

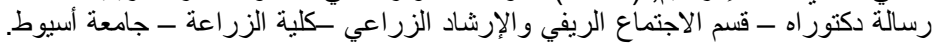

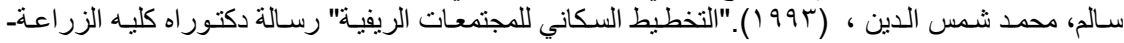

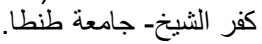

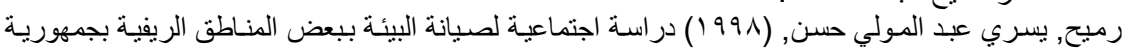

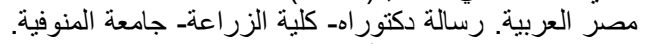

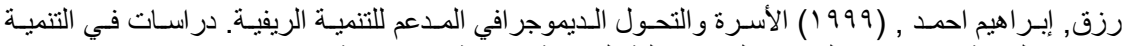

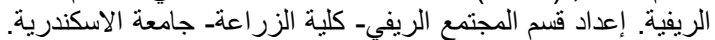

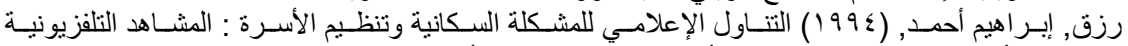

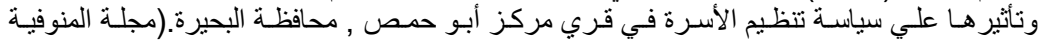

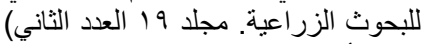

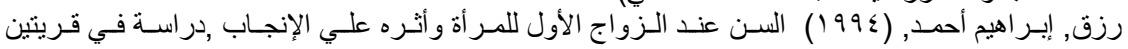

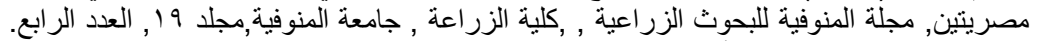

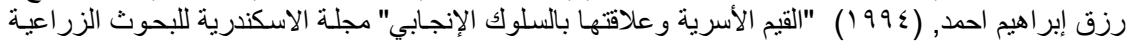

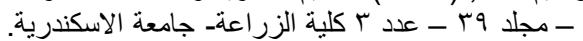

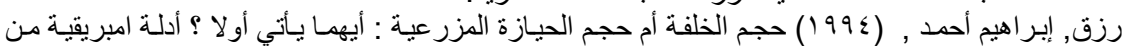

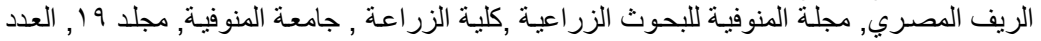

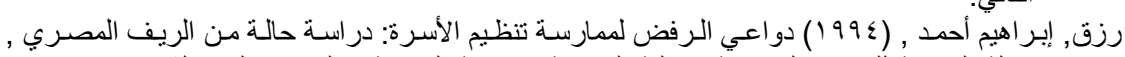

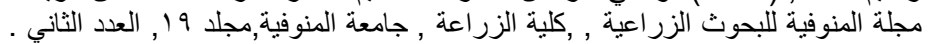

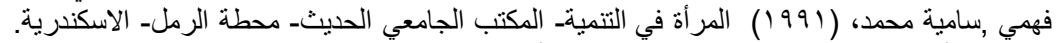

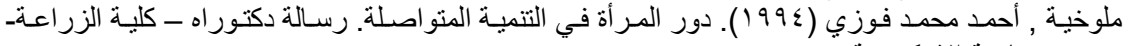

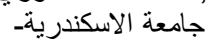

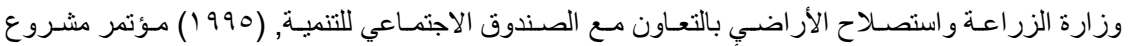

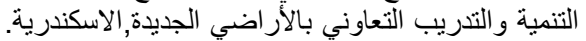

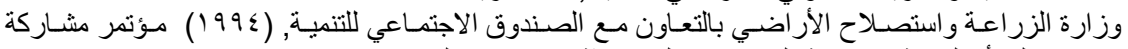
المر أة الريفية في تنمية المجتمعات المستحدثة بالار اضي الني الجديدة.

Kregcie R.V, and Morgan, D .. W., 1970 Educational and Psychological measurement, college station, Durham, North Carolina, USA.

\section{A COMPARATIVE STUDY OF THE DETERMINANTS OF THE RURAL WOMEN'S REPRODUCTIVE BEHAVIOR AT MINUFIYA AND ASSUIT GOVERNORATES \\ Hassan, Nagwa A. \\ Dept. of Agricultural Extension and Rural Sociology, Faculty of Agriculture, Minufiya University, Shibin El-Kom, Egypt}


Hassan, Nagwa A.

\begin{abstract}
This research aimed at determining the levels of the rural women's reproductive behavior at Minufiya and Assuit governorates, and determining the differences of significance between the rural women in each of the two governorates, with regard to their reproductive behavior.

In addition to examine the studied independent variables' relation to the scores of the rural women's reproductive behavior, and determine the relative contribution of some independent variables in explaining the variance that occur in the reproductive behavior of rural women in both governorates as well. Two villages from each governorate were selected. 150 respondents were selected from each governorate. Data had been collected by personal interviewing questionnaire. data had been analyzed by using : simple correlation, T-test, stepwise regression, ratios and frequencies. Also this study aimed at knowing the sources of information the rural women get about "Family Planning" at Minufiya and Assuit governorates. The results revealed that :four independent variables contributed in explaining the variance in the reproductive behavior of rural women in Minufiya governorate: they were: month income of the respondent, attitude towards family planning, average years of education of the family members of the respondent and respondent cosmopolitness. As for Assuit governorate ; four independent variables contributed in explaining the variance of the reproductive behavior of rural women. They were : age of respondents, years of respondents' education , degree of satisfaction of community services and education of the family members of the respondent. The results revealed also that television was the most important source of information about family planning for rural women in both governorates. Finally the research ended with some important recommendations .
\end{abstract}

